\title{
The Bispectral Index Interest during General Anesthesia at the University Hospital of Parakou (Republic of Benin) in 2019
}

\author{
Tchaou Blaise Adelin ${ }^{1 *}$, Tchégnonsi N'vènonfon Charles Frédéric ${ }^{1}$, \\ Ezadjomo Evouna Ndoh Agnès Nina1 ${ }^{1}$, Zoumenou Eugene' ${ }^{1}$, Brouh Yapo ${ }^{2}$, Chobli Martin
}

${ }^{1}$ Department of Anesthesia-Resuscitation and Emergency, Borgou-Alibori University Hospital Center, Parakou, Benin ${ }^{2}$ Anesthesia-Resuscitation and Pediatric Emergencies, Hospital of Mother and Child of Bingerville, Bingerville, Rep. Cote d'Ivoire Email: ${ }^{*}$ tchblaise@yahoo.fr

How to cite this paper: Adelin, T.B., Frédéric, T.N.C., Nina, E.E.N.A., Eugene, Z., Yapo, B. and Martin, C. (2021) The Bispectral Index Interest during General Anesthesia at the University Hospital of Parakou (Republic of Benin) in 2019. Open Journal of Anesthesiology, 11, 59-71.

https://doi.org/10.4236/ojanes.2021.113007

Received: January 18, 2021

Accepted: March 19, 2021

Published: March 22, 2021

Copyright $\odot 2021$ by author(s) and Scientific Research Publishing Inc. This work is licensed under the Creative Commons Attribution International License (CC BY 4.0).

http://creativecommons.org/licenses/by/4.0/

\begin{abstract}
Background: The bispectral index (BIS) derived from the electroencephalogram is an additional means of monitoring the depth of narcosis. Objective: To compare the monitoring of the depth of narcosis by the BIS associated with clinical data versus standard monitoring at the University Hospital of Parakou in Benin in 2019. Methods: This was an observational study for descriptive and analytical purposes with prospective data collection, carried out in general surgery and intensive care unit for 4 months. The inclusion criteria were: an age $\geq 18$ years, an ASA score $\leq 3$, surgery under general anesthesia and informed consent of the patient. Two groups were formed: non-BIS group monitored by clinical parameters (PA, FC, FR, $\mathrm{EtCO}_{2}$, and $\mathrm{SpO}_{2}$ ) only and BIS group monitored by bispectral index in addition to clinical parameters. Patients were seen 48 hours after the procedure. Results: 36 patients were collected. The mean age was $40.63 \pm 16.77$ years with a sex ratio of 3 . ASA 1 patients represented $86.11 \%$ of the sample and ASA2 patients $13.89 \%$. The average doses of Propofol were not significantly reduced in the BIS group $(\mathrm{p}=0.555)$. On the other hand, the period of intraoperative recovery ( $\mathrm{p}$-value $=0.007)$ and the NVPO $(p=0.043 ;$ OR $=0.10 ; 95 \%$ CI $[0.01-0.97])$ were significantly reduced by the use of BIS. One case of intraoperative memorization (2.78\%) was however found in the BIS group. Conclusion: The bispectral index makes it possible to significantly reduce the risk of intraoperative awakening and PONV, and not significantly reduce the consumption of Propofol.
\end{abstract}

\section{Keywords}

General Anesthesia, Narcosis, Bispectral Index, Monitoring 


\section{Introduction}

General Anesthesia (GA) is widely used during surgical procedures in operating theaters. According to the French Society of Anesthesia and Resuscitation (SFAR), it is a state comparable to sleep induced by the injection of drugs intravenously and/or by inhalation [1]. It is a medical act that aims to immerse the patient in a deep and artificial sleep (narcosis) while depriving him of painful sensations in order to perform surgery and medical explorations which may be unpleasant. Monitoring the depth of this sleep has long been a concern for anesthesiologists because of the morbidity and mortality associated with a poor dosage of anesthetic drugs, the administration of which depends on many parameters (age, weight, sex, history, and pathologies in question).

Study setting: The operating theaters of the general surgery ward and the postinterventional care and resuscitation units served as the study setting. For many years, clinical monitoring has been the only technique for monitoring the depth of narcosis. But its fluctuation revealed its insufficiency due to the lack of knowledge of certain patients' medical histories. In order to improve the monitoring's quality, new neurophysiological monitoring techniques have been invented and among them, the bispectral index (BIS) which is currently the most widely used. The bispectral index is a derivative of the electroencephalogram (EEG) that provides anesthesiologists with an additional way to monitor the depth of narcosis. In France, according to Maugars, this device is known to most anesthetist staff (nurses, interns, doctors) but is only used by $10 \%$ of them [2].

Numerous studies have identified the various advantages associated with the use of this technique. Consequently, in the United States in 2004, Liu in a meta-analysis including all the randomized controlled studies comparing BIS surveillance with standard clinical practice in outpatient surgery found an overall reduction of $19 \%$ in the use of anesthetics during surveillance by the BIS [3]. In 2017 in Brazil, Oliveira et al., in a Meta-analysis carried out over a period of two (2) years from December 2013 to January 2015, reported 1\% reduction in the risk of memorization and an overall reduction of $12 \%$ in risk of Post-Operative Nausea and Vomiting (PONV) if general anesthesia is monitored by BIS [4]. In Africa, the use of this new technique is not frequent. In Burkina-Faso, Lankoande et al., in 2017 found a risk of memorization of $1.4 \%$ when the monitoring of the depth of the narcosis was carried out only by clinical parameters [5]. Based on this observation, it seemed necessary to us to initiate this word, the objective of which is to compare the monitoring of the depth of narcosis by BIS associated with clinical data versus standard monitoring.

\section{Patients and Method}

Study method Type and period of study: This was an observational study with a descriptive and analytical aim with prospective data collection carried out over a period of 4 months (April 10 to August 10, 2019) and whose protocol was submitted to the ethics committee of the faculty of medicine and validated accord- 
ing to the number (REF 285/CLERB-UP/P/SP/R/SA). Study population: It consisted of patients operated on in the operating theaters of the general surgery department and followed in the post-intervention care room or in intensive care. Inclusion criteria: were included in the study the patients of age greater than or equal to 18 years, having an ASA score less than or equal to 3, requiring a surgical act under general anesthesia and having given their consent or that of their family to participate in the study. Exclusion criteria: patients with a history of central nervous system pathology capable of inducing changes in the electroencephalogram were excluded. Non-inclusion criteria: patients not eligible for BIS were not included (limits for using BIS: in particular certain cases of neurosurgery). Sampling: An exhaustive recruitment was carried out of all patients admitted for scheduled or urgent surgery during the study period and fulfilling the inclusion criteria. The variables studied were of two types: a dependent variable and independent variables. Dependent variable: this was the tracing of the bispectral index which is a derivative of the electroencephalogram allowing the assessment of the depth of the narcosis.

\subsection{Independent Variables}

Socio-demographic data: age, sex. Clinical data: medical, surgical and anesthetic history, drug allergies), ASA score, type of surgery, surgical specialties.

Data on general anesthesia: induction (type and dose of hypnotic used, type and dose of curare used, type and dose of analgesic used), intubation, mode of ventilation, duration of the maintenance phase, duration of treatment anesthesia (short or long term).

Data related to the general anesthesia monitoring: vital constants (temperature, blood pressure, heart rate, respiratory rate, $\mathrm{SpO}_{2}, \mathrm{EtCO}_{2}$, pupil diameter), incidents observed intraoperatively (erythema, anaphylactic shock, hypotension, awakening intraoperative, respiratory depression). Evolving data: awakening (time, type), time to open the eyes, time of the oriented verbal response, the time to be oriented in time and space, the time to leave the block, the occurrence of PONV, memorization risk and death. Data collection: the data was collected during the pre-anesthetic consultation or the pre-anesthetic visit by questioning the patients then consulting the medical files and direct observation throughout the surgery. Forty-eight (48) hours after the operation, an interview with the patients made it possible to note the postoperative complications and the data were recorded on a pre-established questionnaire.

Sampling procedure: the patients were divided into two groups and benefited from a general anesthesia technique adapted to the surgical procedure and their characteristics (weight, history), without changing the habits of the anesthetist staff. This involved distributing all the patients falling within our inclusion criteria randomly and alternately (1-1) into the two groups. The first group called group A or control group consisted of patients whose General Anesthesia (GA) was monitored only by clinical parameters, namely: Pupil Diameter, Arterial 
Pressure (BP), Heart Rate (HR), Respiratory Rate (RF), pulsed $\mathrm{O}_{2}$ saturation $\left(\mathrm{SpO}_{2}\right)$, and expired $\mathrm{CO}_{2}$ fraction $\left(\mathrm{EtCO}_{2}\right)$. The second group, called group $\mathrm{B}$ or BIS group, consisted of patients whose GA was monitored by the bispectral index, in addition to the clinical parameters mentioned above. The investigation in the operating theater consisted of noting, after observation, the practice of anesthesia (anesthetics used, doses) and the patient's reaction during the operation (values of vital constants, BIS value every $30 \mathrm{~min}$ in the event of GA short term and every $60 \mathrm{~min}$ in case of long term GA, intraoperative awakening).

For the group B, the BIS was measured using a sensor called BIS TM Quatro (XP TM Platform) made up of 4 electrodes placed on the patient's forehead in the following order $1,2,4,3$ of the from the right to the left, and the arrangement of which was carried out as follows:

After having cleaned the patient's forehead with alcohol and then dried with a compress, we positioned the sensor diagonally on the forehead as follows: Electrode \# 1 was placed in the middle of the forehead about $5 \mathrm{~cm}$ above the root of the nose, Electrode 2 was placed directly above the left or right eyebrow. Electrode 4 was on the left or right temple, between the corner of the eye and the contour of the hair. Electrode 3 was placed laterally in front of the left or right eye (Figure 1). Then we held the 4 electrodes 1, 2, 4, 3 firmly on the skin for about 5 seconds to ensure a good grip. Then the sensor clip was inserted into the patient cable. Each electrode was for single use and supplied by us. The sensor was positioned just before induction and the BIS reading was taken after the start of induction which was considered for a value of BIS $\leq 40$. During the maintenance phase, the BIS was maintained between 40 and 60 .

For each group, the level of narcosis and the anesthetic doses were readjusted according to the monitoring data (clinical parameters, and the presence of intraoperative movements for group $\mathrm{A}$, and in addition the BIS values for group B). Immediately postoperatively, we appreciated the awakening (type, time to open eyes, verbal response, temporo-spatial orientation). Forty-eight (48) hours later, an interview with the patient made it possible to search for postoperative complications, namely PONV, memorization through 3 questions taken from the questionnaire by Brice et al. [6].

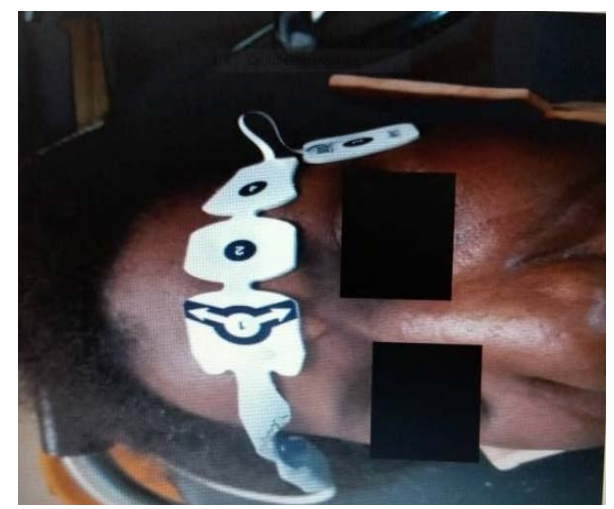

Figure 1. BIS Quatro electrodes placed on the operating table. 


\subsection{Data Processing and Analysis}

The data were entered and analyzed respectively from the software Epi data 3.1 and Stata 14. The percentages, means, or standard deviations as appropriate were used for the presentation of the quantitative variables while the qualitative variables were expressed with proportions. The proportions were compared using the Chi square test (or Fisher's exact test, as the case may be) at the $5 \%$ level.

\section{Results}

During our study period, 413 patients underwent surgery, 260 (62.96\%) under locoregional anesthesia and 153 (37.04\%) under general anesthesia. Of the 153 patients who were operated on under general anesthesia, 55 (35.95\%) were children and 98 (64.05\%) adults, of whom $36(36.73 \%)$ met our inclusion criteria.

\subsection{Socio-Demographic Data}

The mean age was $40.63 \pm 16.77$ years with extremes between 18 and 87 years. Male patients represented $75 \%(\mathrm{n}=27)$ versus 9 females $(25 \%)$ with a sex ratio of 3 .

\subsection{Clinical Data}

In our series, no patient had a surgery history or an anesthetic. Twenty-eight patients $(77.78 \%)$ had no medical history. The medical histories collected were: 3 cases of high blood pressure (8.33\%), 3 cases of diabetes (8.33\%), and 2 cases of renal failure (5.56\%). Regarding the ASA score, 31 patients (86.11\%) had an ASA 1 score and 5 patients (13.89\%) had an ASA 2 score. Scheduled interventions represented $44.44 \%(n=16)$ against $55.56 \%(n=20)$ of emergency interventions. Table 1 shows the distribution of patients according to surgical specialties in the two groups.

\subsection{Data on General Anesthesia}

Table 2 shows the distribution of patients according to the types of hypnotics used in the induction and maintenance phases.

Table 3 shows the distribution of the average doses of hypnotics used according to the induction phase and the maintenance phase.

Table 1. Patients distribution according to the two groups' diagnosis.

\begin{tabular}{ccc}
\hline Diagnostics & BIS Group (number/\%) & non BIS Group (number/\%) \\
\hline Visceral surgery & $9(25.00 \%)$ & $8(22.22 \%)$ \\
Traumatology & $3(8.33 \%)$ & $3(8.33 \%)$ \\
Neurotraumatology & $2(5.56 \%)$ & $4(11.12 \%)$ \\
Urology & $3(8.33 \%)$ & $0(0.00 \%)$ \\
ORL & $1(2.78 \%)$ & $3(8.33 \%)$ \\
Total & $18(50.00 \%)$ & $18(50.00 \%)$
\end{tabular}


Table 2. Distribution of patients according to the types of hypnotics used in the induction and in maintenance phase.

\begin{tabular}{ccccc}
\hline & Total & \multicolumn{2}{c}{ Groups } & p-value \\
\cline { 3 - 3 } & & BIS (\%) & Non BIS (\%) & \\
\hline Propofol & $17(47.22)$ & $6(16.67)$ & $11(30.55)$ & 0.095 \\
Thiopental & $17(47.22)$ & $11(30.55)$ & $6(16.67)$ & 0.095 \\
Ketamine & $5(13.89)$ & $2(5.56)$ & $3(8.33)$ & 0.171 \\
\hline & & Hypnotics in maintenance & \\
Propofol & $12(33.33)$ & $4(11.11)$ & $8(22.22)$ & 0.157 \\
Isoflurane & $15(41.67)$ & $9(25.00)$ & $6(16.67)$ & 0.310 \\
Halothane & $20(55.56)$ & $8(22.22)$ & $12(33.34)$ & 0.180 \\
\hline
\end{tabular}

Table 3. Distribution of the average doses of hypnotics used according to the induction and maintenance phase.

\begin{tabular}{|c|c|c|c|c|}
\hline & \multirow{2}{*}{ Total } & \multicolumn{2}{|c|}{ Groups } & \multirow{2}{*}{ p-value } \\
\hline & & BIS & Non BIS & \\
\hline \multicolumn{5}{|c|}{ Hypnotics in induction } \\
\hline Propofol mg $(\mathrm{n}=17)$ & $144.44 \pm 48.16$ & $135.71 \pm 55.63$ & $150 \pm 44.72$ & 0.555 \\
\hline Thiopental $\mathrm{mg}(\mathrm{n}=17)$ & $504.41 \pm 92.80$ & $529.54 \pm 81.25$ & $458.33 \pm 102.06$ & 0.134 \\
\hline Kétamine mg $(\mathrm{n}=5)$ & 150.00 & 125.00 & 166.67 & - \\
\hline \multicolumn{5}{|c|}{ Hypnotics in maintenance } \\
\hline Propofol mg $(\mathrm{n}=12)$ & $101.66 \pm 78.25$ & $72.5 \pm 38.62$ & $116.25 \pm 90.85$ & 0.386 \\
\hline Isoflurane $\%(\mathrm{n}=15)$ & $1.31 \pm 0.30$ & $1.35 \pm 0.33$ & $1.25 \pm 0.27$ & 0.533 \\
\hline Halothane $\%(n=20)$ & $1.48 \pm 0.59$ & $1.6 \pm 0.78$ & $1.4 \pm 0.43$ & 0.473 \\
\hline
\end{tabular}

\subsection{Other Drugs Used}

Fentanyl was used in all patients at a mean dose of 173.89 micrograms, with extremes of 50 and 200 micrograms. Ketamine was used in analgesic dose in 18 patients (38.89\%) including 9 in BIS group and 9 in non-BIS group in the induction phase. The mean dose was $29.64 \mathrm{mg}$ ( $32 \mathrm{mg}$ for BIS group and $28.33 \mathrm{mg}$ for non-BIS group). Curare was used in 34 patients. Suxamethonium was used in 33 patients $(97.06 \%)$ and Rocuronium in 1 patient $(2.94 \%)$.

\subsection{Intubation and Ventilation}

A total of 34 patients (94.44\%) underwent oro-tracheal intubation: 17 patients (47.22) in BIS group and 17 (47.22) also in non-BIS group). One patient (2.78\%) underwent a laryngeal mask settlement (BIS group) and one patient (non-BIS 
group) was not intubated. All intubated patients received mechanical ventilation.

\subsection{Duration of Anesthesia and Average Duration of the Maintenance Phase}

The duration of anesthesia was short in $66.67 \%$ of cases $(n=24)$ and long in $33.33 \%$ of cases $(\mathrm{n}=12)$. The mean duration of the maintenance phase was 113 $\pm 65.38 \mathrm{~min}$ in general and $112.11 \pm 64.10 \mathrm{~min}$ for BIS group and $113.88 \pm 68.47$ min for non-BIS group $(\mathrm{p}=0.936)$.

\subsection{Data Related to Anesthesia Monitoring}

Table 4 shows the distribution of vital constants according to means and extremes.

\subsection{BIS Intervals}

Table 5 shows the distribution of patients according to BIS intervals.

\subsection{Relationship between BIS and Vital Parameters}

Table 6 shows the relationship between BIS and vital constants.

Table 4. Distribution of vital constants according to means and extremes.

\begin{tabular}{ccc}
\hline Vital constant & Means & Extremes \\
\hline Temperature & 36.02 & $35.3-37.8$ \\
PAS & 96.50 & $50-134$ \\
PAD & 57.69 & $35-88$ \\
FC & 91.94 & $58-177$ \\
FR & 14.19 & $12-26$ \\
$\mathrm{SPO}_{2}$ & 98.69 & $67-100$ \\
$\mathrm{ETCO}_{2}$ & 37 & $25-46$ \\
\hline
\end{tabular}

Table 5. Distribution of patients according to BIS intervals.

\begin{tabular}{ccc}
\hline BIS intervalles & Number & $\%$ \\
\hline$[35-0]$ & 1 & 5.55 \\
{$[32-41]$} & 1 & 5.55 \\
{$[31-67]$} & 1 & 5.55 \\
{$[40-60]$} & 12 & 66.67 \\
{$[40-64]$} & 1 & 5.55 \\
{$[42-62]$} & 1 & 5.55 \\
{$[64-70]$} & 1 & 5.55 \\
Total & 18 & 100
\end{tabular}


Table 6. Relationship between BIS and vital constants.

\begin{tabular}{|c|c|c|c|c|c|c|}
\hline & PAS & PAD & $\mathrm{SPO}_{2}$ & FR & FC & $\mathrm{ETCO}_{2}$ \\
\hline [31 - 67] & 85 & 42 & 100 & 17 & 103 & 41 \\
\hline$[32-41]$ & 61 & 59 & 100 & 12 & 112 & 33 \\
\hline [35 - 0] & 64 & 36 & 67 & 12 & 177 & 25 \\
\hline [40 - 47] & 70 & 40 & 100 & 12 & 90 & 33 \\
\hline [40 - 47] & 123 & 88 & 99 & 14 & 124 & 30 \\
\hline$[40-55]$ & 106 & 61 & 100 & 12 & 60 & 44 \\
\hline$[40-60]$ & 105 & 63 & 100 & 14 & 72 & 33 \\
\hline$[40-60]$ & 79 & 47 & 100 & 14 & 100 & 40 \\
\hline$[40-64]$ & 119 & 86 & 99 & 16 & 83 & 38 \\
\hline$[40-84]$ & 120 & 76 & 99 & 14 & 78 & 35 \\
\hline [41 - 47] & 70 & 35 & 100 & 12 & 92 & 33 \\
\hline$[41-48]$ & 65 & 35 & 100 & 18 & 120 & 45 \\
\hline$[41-55]$ & 107 & 68 & 100 & 12 & 80 & 35 \\
\hline$[42-54]$ & 95 & 37 & 100 & 12 & 100 & 36 \\
\hline$[42-62]$ & 134 & 78 & 99 & 12 & 84 & 31 \\
\hline [49-52] & 107 & 53 & 100 & 12 & 98 & 33 \\
\hline$[52-60]$ & 133 & 85 & 100 & 24 & 80 & 32 \\
\hline$[64-70]$ & 79 & 47 & 100 & 14 & 116 & 40 \\
\hline
\end{tabular}

\subsection{Evolving Data}

\subsubsection{Time to Leave the Operating Theater}

The mean time to leave the operating theater was $20.88 \mathrm{~min}$ for the BIS group and $24.39 \mathrm{~min}$ for the non-BIS group $(\mathrm{p}=0.4651)$.

\subsubsection{Awakening Quality}

Table 7 shows the distribution of patients according to the postoperative recovery time (time taken between the end of the operation and awakening) and the type of wakening.

\subsection{Postoperative Complications}

At 48 hours postoperatively, 26 patients $(76.47 \%)$ did not present with PONV, and among them we identified (15 93.75) in the BIS group against 11 (61.11) in the non BIS with an odd ratio of 1 and $(\mathrm{p}=0.043)$. However, we objectified 8 patients $(25.53 \%)$ who presented episodes of PONV, including 1 patient (06.25\%) from the BIS group and 7 patients ( $38.89 \%$ ) from the non-BIS group with $(\mathrm{p}=0.043 ; \mathrm{OR}=0.10 ; 95 \% \mathrm{CI}[0.01-0.97])$. A case of implicit intraoperative memorization was found in BIS group). 
Table 7. Distribution of patients according to postoperative recovery time (min), type of awakening and postoperative recovery data.

\begin{tabular}{|c|c|c|c|c|c|}
\hline & \multirow{2}{*}{ Total } & \multicolumn{2}{|c|}{ Groups } & \multirow{2}{*}{ OR [IC 95\%] } & \multirow{2}{*}{ p-value } \\
\hline & & BIS & Non BIS & & \\
\hline Duration of awakening & $11.97 \pm 11.45$ & $7.25 \pm 9.09$ & $16.16 \pm 13.70$ & & 0.021 \\
\hline Awakening & & & & & 0.999 \\
\hline No & 2 & $1(5.56)$ & $1(5.56)$ & - & \\
\hline Yes & 34 & $17(47.22)$ & $17(47.22)$ & - & \\
\hline Unquiet Awakening & & & & & 0.051 \\
\hline No & $27(79.41)$ & $15(93.75)$ & $12(66.67)$ & 1 & \\
\hline Yes & $7(20.59)$ & $1(06.25)$ & $6(33.33)$ & $0.13[0.01-1.26]$ & \\
\hline Confused Awakening & & & & & 0.012 \\
\hline No & $25(73.53)$ & $15(93.75)$ & $10(55.56)$ & 1 & \\
\hline Yes & $9(26.47)$ & $1(06.25)$ & $8(44.44)$ & $0.08[0.01-0.77]$ & \\
\hline \multicolumn{6}{|l|}{ Postoperative recovery } \\
\hline Duration of the awakening & $55.97 \pm 61.26$ & $42 \pm 40.84$ & $68.38 \pm 73.93$ & & 0.215 \\
\hline Duration of verbal consciousness & $85.58 \pm 69.63$ & $81.75 \pm 71.16$ & $89 \pm 70.13$ & & 0.767 \\
\hline Temporo-spatial oriented duration & $87.61 \pm 68.44$ & $82 \pm 71.09$ & $92.61 \pm 67.66$ & & 0.658 \\
\hline
\end{tabular}

\section{Discussion}

\subsection{Data Related to General Anesthesia}

\subsubsection{Hypnotics Used}

In our series, Propofol and thiopental were the most widely used intravenous hypnotics at induction and in the same proportions (47.22\%), followed by ketamine (13.89\%). These results are different from those of Gaye et al. who reported that thiopental was the most widely used hypnotic $(78 \%)$ in their sample, followed by Propofol (13\%) and finally ketamine (11\%) [7]. Based on the data from the literature and as reported by other authors including Liu et al., Mishra et al., Quan et al. and Kim et al., Propofol remains the most indicated hypnotic in this case because of its quality and its conditions of use (TCI: continuous infusion) which ensure a plateau anesthesia guaranteeing stable narcosis [8] [9] [10] [11]. But its high cost was a factor limiting its use in several patients in our study justifying the use of other hypnotics.

\subsubsection{Hypnotics Doses Used}

In our series, the mean dose of Propofol was $144.44 \pm 48.16 \mathrm{mg}$ at induction and $116.25 \pm 90.85 \mathrm{mg}$ at maintenance. We noted lower mean doses in BIS group (induction: $135.71 \pm 55.63 \mathrm{mg}$; maintenance: $72.5 \pm 38.62 \mathrm{mg}$ ) and greater in non-BIS group (induction: $150 \pm 44.72 \mathrm{mg}$; maintenance: $116.25 \pm 90.85 \mathrm{mg}$ ). This difference, although not significant ( $\mathrm{p}$-value $=0.555$ ) was similar to that reported by other authors including Añez et al. in 2001 and Liu in 2004 who 
noted respective reductions of $32.6 \%$ and $19 \%$ in Propofol consumption when using BIS [12]. The BIS therefore makes it possible to adapt the hypnotic dose in order to keep each patient within their therapeutic range while avoiding anesthetic agents' overdoses.

\subsection{Data related to Anesthesia Monitoring}

\section{The Intraoperative Vital Constants}

The intraoperative vital constants objectified in our series are different from those reported by Gaye et al. in their study (mean heart rate of $92 \mathrm{bats} / \mathrm{min}$ with extremes of 38 and $160 \mathrm{bats} / \mathrm{min}$ and MAP of $96.6 \mathrm{~mm} \mathrm{Hg}$ with extremes of PAS of 70 and $180 \mathrm{~mm} \mathrm{Hg}$ [7] explain by the heterogeneity of the diagnoses retained in our series, but also the long preoperative consultation period responsible for the complications that can lead to multivisceral damage especially hemodynamic, respiratory and metabolic responsible for many complications including arterial hypotension and tachycardia often related to the pre or intraoperative hypovolaemia.

\subsection{BIS Intraoperative Values}

In our series, during the intraoperative period, the BIS value could be maintained within a normal range of (40 - 60) in 12 patients (66.67\%). Three patients (16.67\%) had at least once a BIS value $\leq 35$ and three (16.67\%) a BIS value $\geq 62$. In the latter group, two patients (11.11\%) were unable to be reduced to a BIS value within the normal range despite an increase in the dose of the hypnotic used. First, this is explained by the existence of objects (electric scalpel) which falsely increase the BIS values since no sign of intraoperative awakening was observed in these two patients. The metabolism of hypnotics, which is a function of many factors (age, weight, alcoholism, albuminemia, etc.) which vary from one individual to another, could be the second cause of the phenomenon observed.

\subsection{Relationship between the BIS and Vital Constants}

During our study, a discrepancy was observed between the BIS values and the vital constants. In fact, hemodynamic disturbances, in particular hypotension $(\mathrm{PAS}<90$ and or PAD $<60)$ and tachycardia $(\mathrm{HR}>100)$ which respectively reflect too deep and too light anesthesia were found while the BIS values were in a range interval of [40 - 60]. These results have been reported in the literature by Passot et al. in 2012, Billiards in 2014 and would be justified by the limits of the vital constants to evaluate the depth of the narcosis [13] [14]. In reality, the cases of tachycardia observed with a BIS in normal values are explained by a reduction in analgesia while the cases of hypotension could be linked, firstly to the complications of the diagnoses selected, in particular by the constitution of a third sector in cases of peritonitis or occlusions, secondarily by the surgical act, responsible for a bleeding which could lead to hypovolaemia, and finally by the cardio-depressive activity of hypnotics. 
BIS also enabled us to highlight a cardio-respiratory arrest state, dropping from 35 to 0 , whereas the vital constants, although disturbed, did not allow this diagnosis to be made. It should be noted that the monitor did not always show actual figures at the time of the accident. In other words, even in front of a multiparameter monitor, human vigilance is essential and remains essential when it comes to monitoring anesthesia.

\subsection{Postoperative Recovery}

In our series, the mean time between the end of the intervention and awakening was $11.97 \pm 11.45 \mathrm{~min}$ with a significant difference $(\mathrm{p}=0.021)$ between the BIS group $(7.25 \pm 9.09 \mathrm{~min})$ and the non-BIS group $(16.16 \pm 13.70 \mathrm{~min})$. With regard to the times of awakening and temporo-spatial orientation, the means for each data are lower in the BIS group ( $42 \pm 40.84 \mathrm{~min}$ and $82 \pm 71.09 \mathrm{~min}$ ) compared to those of the group non BIS (68.38 $\pm 73.93 \mathrm{~min}$ and $92.61 \pm 67.66 \mathrm{~min})$. All these results are corroborated by the data in the literature, in particular those of Brhun et al. and Chiang et al. all of which reported a reduction in postoperative recovery time in the BIS group [15] [16] This is explained by the ability of BIS to reduce the consumption of hypnotics by allowing adequate administration of them in time and in dose, thus promoting rapid postoperative recovery of patients.

\subsection{Postoperative Complications}

The PONV was found in our series in 8 patients (25.53\%), i.e. 1 in the BIS group $(06.25 \%)$ and 7 in the non-BIS group (38.89\%) with $\mathrm{p}=0.043(0.10[0.01-$ 0.97]). These results show that BIS reduces the risk of occurrence of PONV by $16.07 \%$. This observation is identical to those made by other authors, in particular Croci et al. in 2014 and Oliviera et al. in 2017 who reported a reduction of $14.70 \%$ and $12 \%$ respectively in the risk of PONV in the BIS group [4] [17]. This is explained by the ability of BIS to keep patients within their therapeutic window, then avoiding any risk of overdose and therefore of PONV. However, this opinion remains mixed, because certain authors, in particular Kim et al. found no significant difference between the two groups [11].

In our series, one case of intraoperative (implicit) memorization was found in the BIS group versus zero in the non-BIS group, despite the number of cases of intraoperative awakening predominant in the latter group. This result is different from that of Myles et al. who reported 2 cases of memorization in the BIS group versus 11 in the non-BIS group [18]. The results we obtained could be justified by the fact that the 48 -hour period we used to search for a possible memorization was insufficient, because it did not optimize the discovery of it. Indeed, Billard in an article on intraoperative memorization at the 51st congress of anesthesia and resuscitation published by the SFAR in 2009 stipulates that this phenomenon can be expressed by the patient from the SSPI room or in some cases several hours or even several. days after waking up [14], hence the relev- 
ance of seeing the patients again at H 24, D2, D14 or even D 30 as some authors have done (Lankoande et al., Myles et al.) [5] [18].

\section{Conclusion}

The BIS monitoring is of real interest during general anesthesia at the Departmental University Hospital of Borgou/Alibori. Indeed, even if authors have had mixed opinions about the use of BIS, this study has highlighted the great advantages of this monitoring device. The BIS makes it possible to detect a dissociation between hemodynamics and the level of anesthesia and/or analgesia, to achieve a better titration of anesthetic agents thus leading to a reduction in their consumption, the risk of occurrence of PONV and intraoperative recovery while ensuring adequate narcosis. BIS also promotes rapid postoperative recovery in favor of better postoperative rehabilitation, which would give a more positive perception of general anesthesia. But the advantages of the BIS are much more physiological than economic because of its high cost, and the lack of health insurance coverage in our context is a disadvantage. This trend can be balanced if a good strategy for using the BIS is settled.

\section{Conflicts of Interest}

The authors declare that they have no conflicts of interest in relation to this article.

\section{References}

[1] Société Française d'Anesthésie et de Réanimation (2019) Information médicale sur l'anesthésie [En ligne].

https://sfar.org/pour-le-grand-public/information-medicale-sur-lanesthesie/

[2] Maugars, C. (2010) Le Monitorage de la profondeur de l'anesthésie: l'index bispectral. [En ligne] https://sofia.medicalistes.fr/spip/IMG/pdf/Monitorage profondeur anesthesie BIS. pdf

[3] Liu, S.S. (2004) Effects of Bispectral Index Monitoring on Ambulatory Anesthesia: A Meta-Analysis of Randomized Controlled Trials and a Cost Analysis. Anesthesiology, 101, 311-315. https://doi.org/10.1097/00000542-200408000-00010

[4] Oliveira, C.R.D., Bernardo, W.M. and Nunes, V.M. (2017) Benefit of General Anesthesia Monitored by Bispectral Index Compared with Monitoring Guided Only by Clinical Parameters. Systematic Review and Meta-Analysis. Brazilian Journal of Anesthesiology, 67, 72-84. https://doi.org/10.1016/j.bjan.2016.10.002

[5] Lankoandé, M., Bonkoungou, P., Konombo, S., Kaboré, A.F.R., Napon, C., Sanou, J., et al. (2017) Réveil peropératoire et mémorisation: prévalence et aspects cliniques dans un Pays Sub-Saharien. European Scientific Journal, 13, 309-322. https://doi.org/10.19044/esj.2017.v13n12p309

[6] Brice, D., Hetherington, R. and Utting, J.E.G. (1970) A Simple Study of Awareness and Dreaming during Anaesthesia. British Journal of Anaesthesia, 42, 535-542.

[7] Gaye, I., Leye, P.A., Traoré, M.M., Ndiaye, P.I., Ba, E.H.B., Bah, M.D., et al. (2016) Prise en charge péri opératoire des urgences chirurgicales abdominales chez l'adulte au CHU Aristide Le Dantec. Pan African Medical Journal, 24, Article No. 190. 
https://doi.org/10.11604/pamj.2016.24.190.9929

[8] Liu, N., Chazot, T., Trillat, B., Dumont, G.A. and Fischler, M. (2007) Titration automatisée du Propofol guidée par l'index bispectral. Annales Françaises d Anesthésie et de Réanimation, 26, 850-854. https://doi.org/10.1016/j.annfar.2007.06.013

[9] Mishra, L.D., Rajkumar, N., Tiwari, A. and Gairola, R. (2007) Role of BIS Monitoring in Propofol Dose Adjustment for Intracranial Tumor Surgery: 7AP1-5. European Journal of Anaesthesiology, 24, 73. https://doi.org/10.1097/00003643-200706001-00268

[10] Quan, C., Chen, J., Luo, Y., Zhou, L., He, X., Liao, Y., et al. (2019) BIS-Guided Deep Anesthesia Decreases Short-Term Postoperative Cognitive Dysfunction and Peripheral Inflammation in Elderly Patients Undergoing Abdominal Surgery. Brain and Behavior, 9, e01238. https://doi.org/10.1002/brb3.1238

[11] Kim, Y.S., Lee, W.K., Choi, Y.S., Chae, Y.K., Ahn, S.W., Lee, A., et al. (2011) A Comparison of the Recovery Characteristics of Propofol-Remifentanil and Desflurane-Remifentanil Anesthesia under Bispectral Index (BIS) Monitoring Following Laparoscopic Cholecystectomy. Anesthesia and Pain Medicine, 6, 331-335.

[12] Añez, C., Papaceit, J., Sala, J.M., Fuentes, A. and Rull, M. (2001) The Effect of Encephalogram Bispectral Index Monitoring during Total Intravenous Anesthesia with Propofol in Outpatient Surgery. Revista Española de Anestesiología y Reanimación, 48, 264-269.

[13] Passot, S. and Molliex, S. (2014) Le BIS vingt ans après? A quoi ça sert? https://icarweb.fr/IMG/pdf/26-le bis 20 ans.pdf [En ligne].

[14] Billard, V. (2014) Le BIS en 2014 une place renaissante. Congrès de Mise Au Point en Anesthésie et Réanimation, Paris.

[15] Bruhn, J., Kreuer, S., Bischoff, P., Kessler, P., Schmidt, G.N., Grzesiak, A., et al. (2005) Bispectral Index and A-Line AAI Index as Guidance for Desflurane-Remifentanil Anaesthesia Compared with a Standard Practice Group: A Multicenter Study. British Journal of Anaesthesia, 94, 63-69.

[16] Chiang, M.H., Wu, S.C., Hsu, S.W. and Chin, J.C. (2018) Bispectral Index and non-Bispectral Index Anesthetics Protocols on Postoperative Recovery Outcomes. Minerva Anestesiologica, 84, 216-228.

[17] Croci, M., Hudecova, S., Fracassi, S. and Greco, S. (2014) Control of the Postoperative Nausea and Vomiting Using a Bispectral Index-Guide Anesthesia and Its Economic Impact: 1AP1-8. European Journal of Anaesthesiology, 31, 5. https://doi.org/10.1097/00003643-201406001-00014

[18] Myles, P., Leslie, K., McNeil, J., Forbes, A. and Chan, M. (2004) Bispectral Index Monitoring to Prevent Awareness during Anaesthesia: The B-aware Randomized Controlled Trial. The Lancet, 363, 1757-1763.

https://doi.org/10.1016/S0140-6736(04)16300-9 